\title{
Microporous Carbon Materials from Bacterial Cellulose for Lithium-Sulfur Battery Applications
}

\author{
Yatong Quan ${ }^{1}$, Dongmei Han ${ }^{2}$, Yuhong Feng ${ }^{1, *}$, Shuanjin Wang $^{2}$, Min Xiao $^{2}$, and Yuezhong Meng ${ }^{2, *}$ \\ ${ }^{1}$ College of Materials and Chemical Engineering, Hainan University, 58 Ren Min Road, Hainan, \\ Haikou 570228, China \\ 2 The Key Laboratory of Low-carbon Chemistry \& Energy Conservation of Guangdong Province/State \\ Key Laboratory of Optoelectronic Materials and Technologies, School of Materials Science and \\ Engineering, Sun Yat-sen University, Guangzhou 510275, P. R. China \\ *E-mail: $\underline{\text { hn136.631@163.com, mengyzh@ mail.sysu.edu.cn }}$
}

doi: $10.20964 / 2017.07 .17$

Received: 21 March 2017 / Accepted: 28 April 2017 / Published: 12 June 2017

The biomass-derived porous carbon materials is one of the most promising sulfur host materials for Li$\mathrm{S}$ batteries applications. This work reports the preparation and application of a novel nitrogen-doped nanostructured microporous carbon materials (NMC) from sustainable bacterial cellulose (BC) subjecting to activation with $\mathrm{KOH}$. The new material has a considerable specific surface area (1479 $\left.\mathrm{m}^{2} \mathrm{~g}^{-1}\right)$ and high pore volume $\left(1.14 \mathrm{~g} \mathrm{~cm}^{-3}\right)$, therefore it exhibits excellent electrical conductivity. The sulfur-NMC (S@NMC) composites based on NMC was synthesized via melt-diffusion method and used as the cathode material in Li-S batteries. The obtained S@NMC composite containing 68.3 wt\% sulfur showed the highest rate capability and long cycling stability. The experiment results also show a high initial discharge capacity of $1267 \mathrm{mAh} \mathrm{g}^{-1}$ and capacity retention of $995 \mathrm{mAh} \mathrm{g}^{-1}$ after 500 discharge/charge cycles at a rate of $0.1 \mathrm{C}$ with a coulombic efficiency of $99.0 \%$.

Keywords: Bacterial Cellulose; Microporous carbon materials; Nitrogen-doped; Lithium-sulfur battery

\section{$\underline{\text { FULL TEXT }}$}

(C) 2017 The Authors. Published by ESG (www.electrochemsci.org). This article is an open access article distributed under the terms and conditions of the Creative Commons Attribution license (http://creativecommons.org/licenses/by/4.0/). 